\title{
Influence of Natural Fibers on the Performance of Hot Mix Asphalt for the Wearing Course of Pavement
}

\author{
Omar T. Mahmood and Sheelan A. Ahmed \\ Department of Civil Engineering, Faculty of Engineering, Koya University, \\ Daniel Mitterrand Boulevard, Koya KOY45 AB64, Kurdistan Region - F.R. Iraq
}

\begin{abstract}
Cracking in the flexible pavement is a serious problem that reduces the service life of the roads pavement unless they are treated with great care. Since flexible pavement is very weaker in tension than in compression, it is usually necessary to consider the tensile stresses and some type of additives to improve asphalt pavement performance, and one of the most effective ways of improving asphalt pavement performance is to reinforce asphalt mixtures by incorporating natural fibers. The main objective of this study is to use palm fiber, which is locally available, in hot mix asphalt mixtures. To achieve this objective, the Marshall test and indirect tensile strength test were conducted on four asphalt mixtures with different types of natural fibers (Coconut, Corn, Palm, and Sisal), added in varying percentages $0.1,0.2,0.3,0.4$, and $0.5 \%$ and different lengths of fiber $0.5,1,1.5$, and $2 \mathrm{~cm}$. Based on the analyzed results, it can be concluded that the use of palm fiber increased the Marshall stability by $20 \%$ as compared with the conventional mixture and raised up the retained tensile strength ratio up to $92 \%$. Finally, the use of $0.2 \%$ content of natural fiber at $1.5 \mathrm{~cm}$ length gave a better performance for the mixtures.
\end{abstract}

Index Terms - Coconut fiber, Corn fiber, Indirect tensile strength, Marshall flow, Marshall stability, Natural fiber, Palm fiber, Sisal fiber.

\section{INTRODUCTION}

Reflection cracking is one of the major distresses that occur frequently in asphalt, concrete overlay in which the existing cracking pattern from the old pavement propagates into and through the new overlay. Cracking occurs because bituminous layers are weak in tension. Therefore, the use of fibers has received considerable attention as viable solutions to enhance flexible pavement performance (Abdelaziz and Mohamed, 2010).

Gazia and Sukhmanjit (2017) used two types of fibers (bamboo fiber and cellulose fiber) to study the resistance of permanent deformation of stone matrix asphalt mixes with four different aggregate gradations. It was observed

\section{ARO-The Scientific Journal of Koya University}

Vol. VIII, No.2 (2020), Article ID: ARO.10710, 7 pages

DOI:10.14500/aro.10710

Received: 05 August 2020; Accepted: 07 November 2020

Regular research paper: Published: 07 December 2020

Corresponding author's e-mail: sheelan.abdulwahid@koyauniversity.org

Copyright (C) 2020 Omar T. Mahmood and Sheelan A. Ahmed. This is an open-access article distributed under the Creative Commons Attribution License. that the bituminous mixes containing bamboo fiber as fillers are found to have Marshall properties almost the same as of cellulose fiber fillers. Where, both of them have a positive effect on the properties of bituminous mixtures by increasing its stability and voids and decreasing the flow value. In addition to filling the voids, the fillers' components interact with the binder present in the mix, potentially making it stiff and brittle. Kavalakuntle and Praveen (2016) studied the drain down analysis, static indirect tensile strength test, and static creep test to evaluate the effects of sisal fiber addition on bituminous concrete and stone mastic asphalt (SMA) performance. By Marshall method, the optimum fiber content for both mixes was found to be $0.3 \%$. Based on the results and discussions of experimental investigations carried out, the addition of sisal fibers improves the Marshall stability, drain down characteristics, and indirect tensile strength of both mixes, especially the SMA, which gave better indirect tensile strength and creep characteristics. Furthermore, a previous study by Bindu and Beena (2015) investigated the influence of natural fibers, which were sisal, coir, and banana fibers, on the compressive strength of SMA mixture. The results showed that the maximum value of compressive strength is achieved at $0.3 \%$ fiber content. Ashraf (2012) added polypropylene and aramid fibers to the asphalt binder and mixture, with sixteen different dosages and blends of fibers. The results indicated that the blend of three dosages of polypropylene and one dosage of aramid gave the best viscosity of binder and the lowest viscosity-temperature relationships value indicating a lesser temperature susceptibility to both permanent deformation and thermal cracking. On the other hand, the aramid fiber gave better results than the polypropylene fiber to resist the indirect tensile force.

Saswat and Mahabir (2016) experimentally investigated the dense-graded bitumen mixes with bottom ash (as part of fine aggregate), fly ash (as mineral filler), and sisal fiber as an additive to enhance the engineering properties of the bituminous paving mix. Four different percentages of sisal fiber $0.25 \%, 0.5 \%, 0.75 \%$, and $1.0 \%$ by weight of the mix were used, with different lengths $(5,10,15$, and $20 \mathrm{~mm}$ ). The results showed that the use of fiber content up to $0.5 \%$ with fiber length $10 \mathrm{~mm}$ increased Marshall stability, whereas air voids and Marshall flow decreased, 
also indirect tensile strength increased due to the addition of emulsion coated fiber. Sigit (2013) studied the effects of short coconut fibers on the binder rheological properties and Marshall stability, moisture susceptibility, and rutting performance of asphalt mixture, the coconut fiber was cut to lengths of $5 \mathrm{~mm}, 7.5 \mathrm{~mm}, 10 \mathrm{~mm}$, and $12.5 \mathrm{~mm}$ and added to the bitumen of grade $60 / 70$ in levels of $(0.5,0.75,1$, 1.25 , and $1.5 \%$ ). The tests showed that the addition of short coconut fiber reduced the penetration grade of bitumen and ductility but increased the softening point; also, specimens prepared by $0.75 \%$ coconut fiber asphalt performed better than asphalt mixtures using virgin asphalt. Hossam and Khalifa (2005) compared the effect of palm fibers and textile fibers, in combination with styrene-butadiene rubber (SBR) polymer on the properties of open-graded friction course mixture. The results indicated that the asphalt mix containing palm fibers and SBR polymer at $5.0 \%$ and the asphalt mix containing textile fibers and SBR polymer at $6.5 \%$ asphalt content satisfied the mix design criteria. That the previous studies in this field indicate that adding fibers have a positive role in improving the performance of asphalt mixtures. As it is known that Iraq has millions of palm trees and due to the large quantities of fibers produced from them annually, it is necessary to think about using them in a way that might be economically beneficial for improving the performance of the hot asphalt mixtures used in paving roads locally. For this purpose, it was necessary to investigate the effect of adding palm fibers on the performance of asphalt mixtures by comparing them with natural fibers used in previous studies such as sisal, corn, and coconut fibers, and determining whether palm fibers behave such as these fibers in improving the performance of asphalt mixtures or do they behave in a different way.

\section{Materials Characterization}

All materials used in this study are locally available and currently used in road construction in northern Iraq except the fibers. Since fibers have higher tensile strengths compared to bituminous mixtures, there is a possibility that they to enhance the cohesive and tensile strength of bituminous mixes (Brown, et al., 1990)

\section{A. Aggregates}

In this study, aggregates are used an asphalt concrete mixture, in which $19 \mathrm{~mm}$ maximum size dense gradation has been selected according to State Corporation of Roads and Bridges (State Organization of Road and Bridges, 2007). The coarse and fine aggregate used in this investigation was brought from the Darbande Zeoi quarry near Sulaymaniyah city in Iraq and crushed at the local asphalt concrete mix plant by mechanical crusher. The aggregate gradation is shown in Table I. An ordinary Portland cement was used as mineral filler.

\section{B. Asphalt Cement}

The currently used asphalt cement with penetration grade of 40-50 from Baiji refinery. The characteristics of asphalt are meeting the standards of State Corporation of Roads and Bridges (SORB, 2007). The physical properties of the asphalt samples are given in Table II.

\section{Natural Fiber}

Hot mix asphalt (HMA) is strong in compression and weak in tension, then fibers reinforcement could be used to provide needed resistance to tensile stresses. For this purpose, four different types of natural fibers were used in this research coconut, corn, palm, and sisal fiber with various lengths 0.5 , $1.0,1.5$, and $2.0 \mathrm{~cm}$ and added by five different contents 0.1 , $0.2,0.3,0.4$, and $0.5 \%$ by total weight of the mixture. The selected of these small percentages can be attributed to the lightweight of the natural fibers. Fig. 1a shows coconut fiber, which is a natural fiber extracted from the husk of coconut and used in products such as floor mats, doormats, and brushes. Coconut fiber is the fibrous material found between the hard internal shell and the outer coat of a coconut. They are naturally brown in color, having a coarse and thick nature but durable fiber, strong, and good abrasion resistance. Corn fiber shown in Fig. 1b has similar characteristics to polyester staple fiber. Corn fiber has very good flex, moisture retrieve, and good heat resistance, and it has full luster and elasticity (Reena, et al., 2009). Sisal fiber, which is shown in Fig. 1c, is one of the most widely used natural fiber and it could be can be cultivated effortlessly. It is obtained from the sisal plant. Palm fibers, which are shown in Fig. 1d, have large clearances among a mass of thick fibers are collected. These fibers being fixed to one another firmly by resin, the resultant product being reinforced by unitarily combining therewith by a resin a knitted comprising natural vegetable fiber of high tensile strength.

TABLE I

Selected Combined Gradation of Aggregate and Filler According to SORB SPECIFICATIONS

\begin{tabular}{lcc}
\hline \hline Sieve size & Specification range & Selected gradation \\
\hline $3 / 4 "$ & 100 & 100 \\
$1 / 2 "$ & $90-100$ & 95 \\
$3 / 8 "$ & $76-90$ & 83 \\
No.4 & $44-74$ & 59 \\
No.8 & $28-58$ & 43 \\
No.50 & $5-21$ & 13 \\
No.200 & $4-10$ & 7 \\
\hline \hline
\end{tabular}

TABLE II

Physical Properties of Asphalt Cement

\begin{tabular}{lcccc}
\hline \hline Properties & Unit & Specifications & $\begin{array}{c}\text { Test } \\
\text { results }\end{array}$ & $\begin{array}{c}\text { Specifications } \\
\text { limits }\end{array}$ \\
\hline $\begin{array}{l}\text { Penetration at } \\
\left(25^{\circ} \mathrm{C}, 100 \mathrm{~g}, 5 \mathrm{~s}\right)\end{array}$ & $0.1 \mathrm{~mm}$ & ASTM D5 & 46 & $40-50$ \\
$\begin{array}{l}\text { Specific gravity at } 25^{\circ} \mathrm{C} \\
\text { Softening point (Ring and }\end{array}$ & ${ }^{\circ} \mathrm{C}$ & ASTM D36 & 55.6 & --- \\
Ball) & & & & \\
$\begin{array}{l}\text { Ductility } \\
\left(25^{\circ} \mathrm{C}, 5 \mathrm{~cm} / \mathrm{min}\right)\end{array}$ & $\mathrm{cm}$ & ASTM D113 & 103 & $>100$ \\
$\begin{array}{l}\text { Flash point } \\
\text { Fire point }\end{array}$ & ${ }^{\circ} \mathrm{C}$ & ASTM D92 & 285 & $>232$ \\
\hline \hline
\end{tabular}



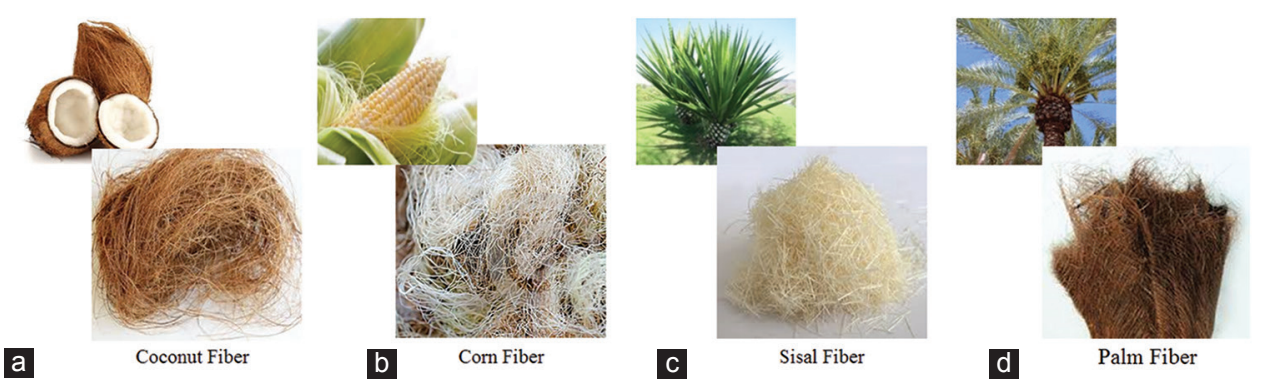

Fig. 1. Different types of natural fibers.

\section{Laboratory Specimen Preparation and Test Methods}

\section{A. Optimum Asphalt Content}

Marshal specimens were prepared per each type of natural fiber in accordance with the Marshall procedure specified in ASTM D6926-10 with different percentages of asphalt cement varying from $4 \%$ to $6 \%$ at an increment of $0.5 \%$ mixed with the aggregates and Portland cement filler according to the adopted gradation. The Marshall samples were extracted from the mold after the specimens were brought to room temperature and thereafter tested in accordance with ASTM D6927-15 procedure. The test results are represented in Figs. 2-5, which showed optimum asphalt contents per each mixture.

\section{B. Effect of Natural Fiber Type}

The effect of natural fiber types on the performance of HMA is evaluated through the comparisons the behavior of specimens with four different types of natural fibers (coconut, corn, sisal, and palm fiber) in which a fiber length of $1.0 \mathrm{~cm}$ added by $0.3 \%$ of the total weight of the mixture. Two optimum asphalt contents were used, one of them selected in correspondence with air voids $4 \%$ to compensate the absorbed asphalt by the natural fibers, and the other optimum asphalt content selected according to maximum Marshall stability to determine the optimum effect of each type of natural fibers. The results of the Marshall tests are shown in Figs. 6-9. The performance of the mixtures per each type of natural fiber showed an increment in the asphalt content, especially for the fiber with wooden texture such as palm and coconut, and also improved the Marshall properties as compared with the conventional mixture, whereas the sisal and palm fibers gave better performance.

The tensile characteristics of HMA per each type of natural fiber are evaluated by loading the Marshall specimen along a diametric plane with a compressive load at a constant rate acting parallel to and along the vertical diametrical plane of the specimen through two opposite loading strips. This loading configuration develops a relatively uniform tensile stress perpendicular to the direction of the applied load and along the vertical diametrical plane, ultimately causing the tested specimen to fail by splitting along the vertical diameter. The static indirect tensile strength of a specimen is determined using the procedure outlined in ASTM D 6931. The tensile strength ratio depending on the result of indirect tensile strength in two cases (conditioned and unconditioned)

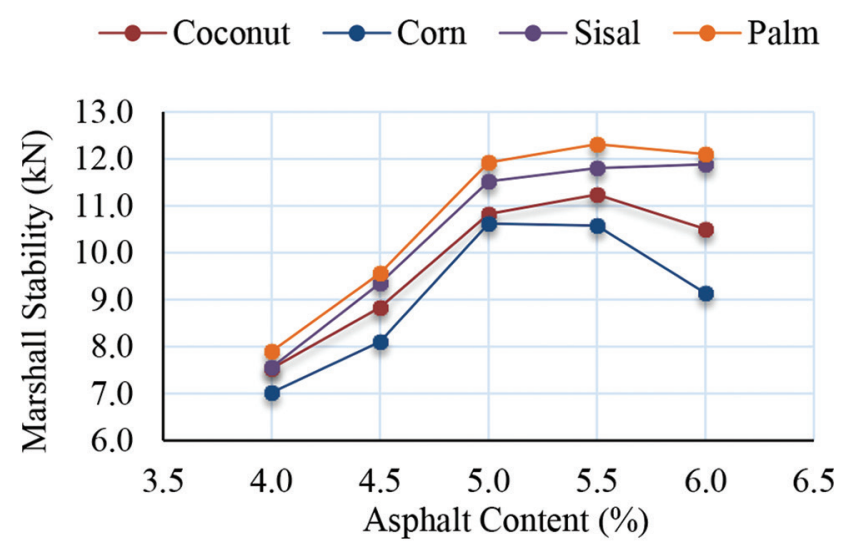

Fig. 2. Effect of asphalt content on Marshall stability of the mixture per each type of natural fibers.

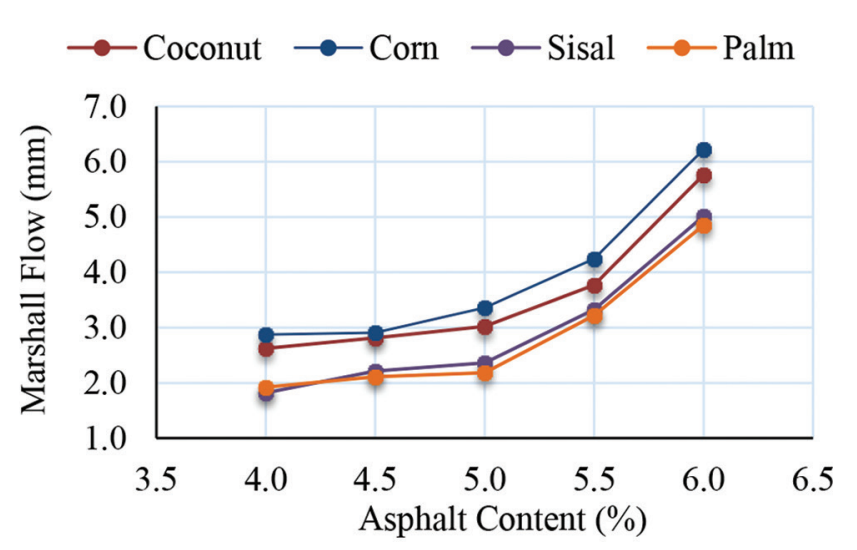

Fig. 3. Effect of asphalt content on Marshall flow of the mixture per each type of natural fibers.

as shown in Table III and represented in Figs. 10 and 11. The results indicate that adding natural fiber increases the indirect tensile strength and tensile strength ratio, especially for the sisal and palm fibers. This can be attributed to the increased amount of the asphalt content due to the effect of different texture of fibers.

\section{Effect of Natural Fiber Content}

Five different percentages of the sisal and coconut fibers $(0.1,0.2,0.3,0.4$, and $0.5 \%)$ with $(1.0 \mathrm{~cm})$ length were added to the HMA to determine the optimum content of natural fibers. The Marshall test results represented in Figs. 


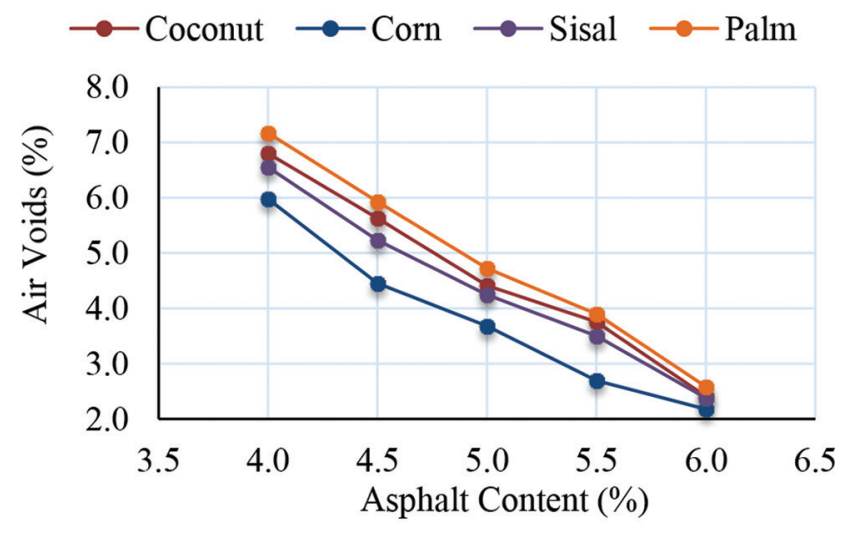

Fig. 4. Effect of asphalt content on air voids of the mixture per each type of natural fibers.

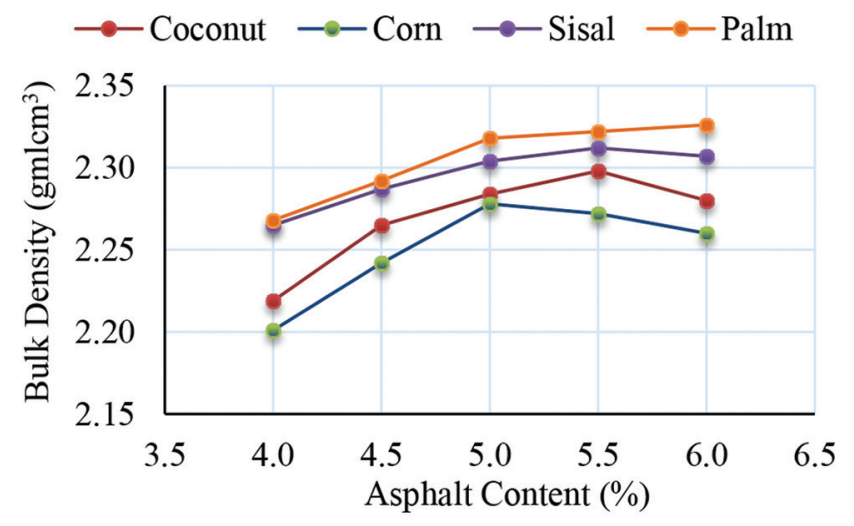

Fig. 5. Effect of asphalt content on bulk density of the mixture per each type of natural fibers.

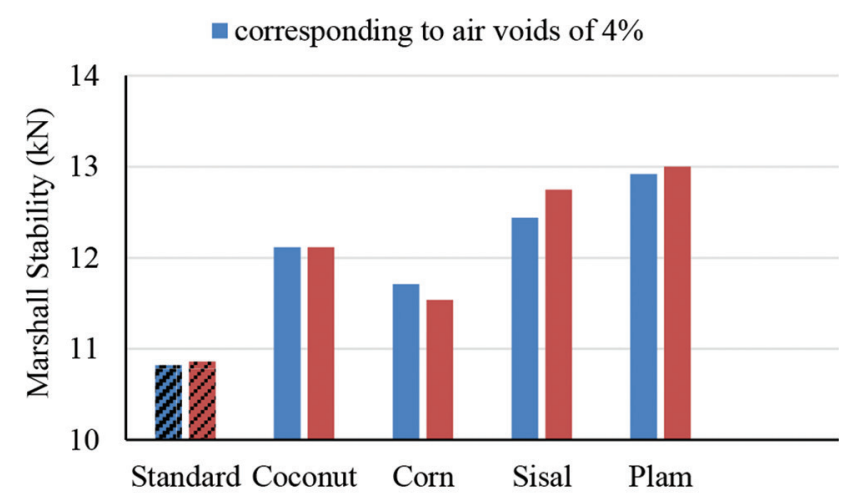

Fig. 6. Effect of fiber type on Marshall stability.

12-15 shows that when the natural fibers content is increased, the Marshall stability, Marshall flow, and the percentage of voids filled asphalt decrease, whereas the air voids increase. There existed that the optimum percentage of sisal fiber content $(0.2 \%)$ for Marshall stability; this can be attributed that the increase of fibers content in the mixture leads to reduce the contact points between aggregate, hence resulting in lower stability.

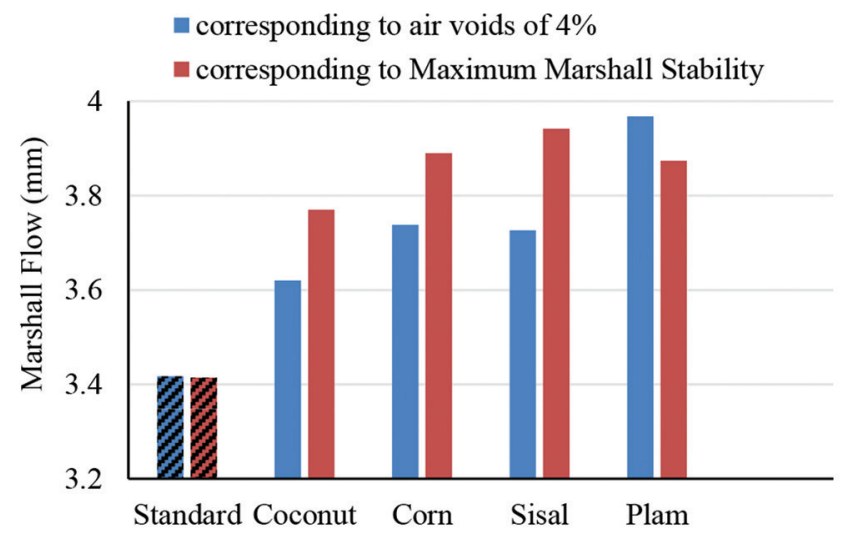

Fig. 7. Effect of fiber type on Marshall flow.

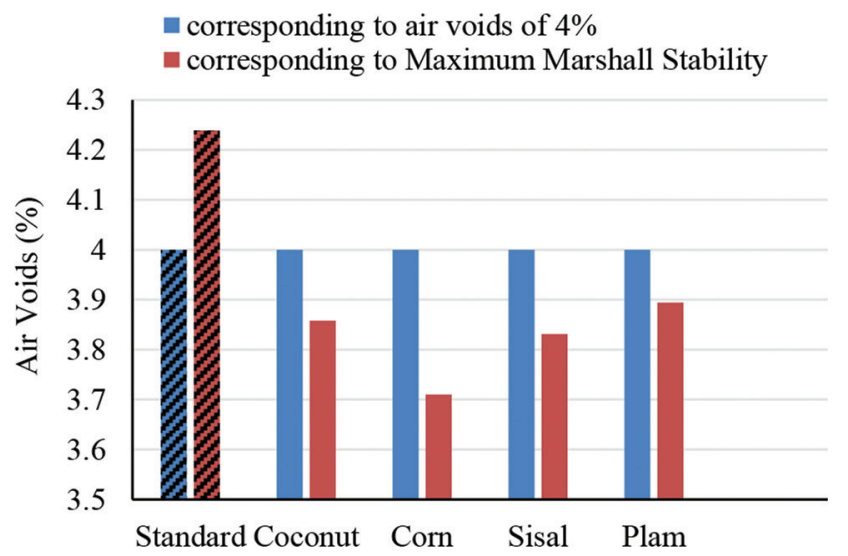

Fig. 8. Effect of fiber type on air voids.

TABLE III

Indirect Tensile Strength Results for Different types of Natural FIBERS

\begin{tabular}{lccccc}
\hline \hline Item & Standard & \multicolumn{4}{c}{ Natural fiber } \\
\cline { 3 - 6 } & & Coconut & Corn & Sisal & Palm \\
\hline $\begin{array}{l}\text { Asphalt content } \\
\text { corresponding to air voids } \\
\text { of } 4 \%\end{array}$ & 4.9 & 5.5 & 5.3 & 5.6 & 5.7 \\
$\begin{array}{l}\text { Indirect tensile strength - } \\
\text { unconditioned (MPa) }\end{array}$ & 2.619 & 2.737 & 2.692 & 2.796 & 2.790 \\
$\begin{array}{l}\text { Indirect tensile strength - } \\
\text { conditioned (MPa) }\end{array}$ & 2.102 & 2.322 & 2.413 & 2.550 & 2.448 \\
\begin{tabular}{l} 
Tensile strength ratio (\%) \\
\hline \hline
\end{tabular} & 80.259 & 84.837 & 89.636 & 91.202 & 87.742 \\
\hline
\end{tabular}

The indirect tensile test results, shown in Figs. 16 and 17, indicated that adding fibers up to $0.3 \%$ into the standard mixes reasonably improves its tensile behavior as compared to the standard mix. This is probably due to the good distribution of fibers in different directions of asphalt mixture and that leads to provide a good resistance to the tensile force.

\section{Effect of Natural Fiber Length}

The effect of the natural fiber length on the performance of the asphalt mixture has been studied by adding the 


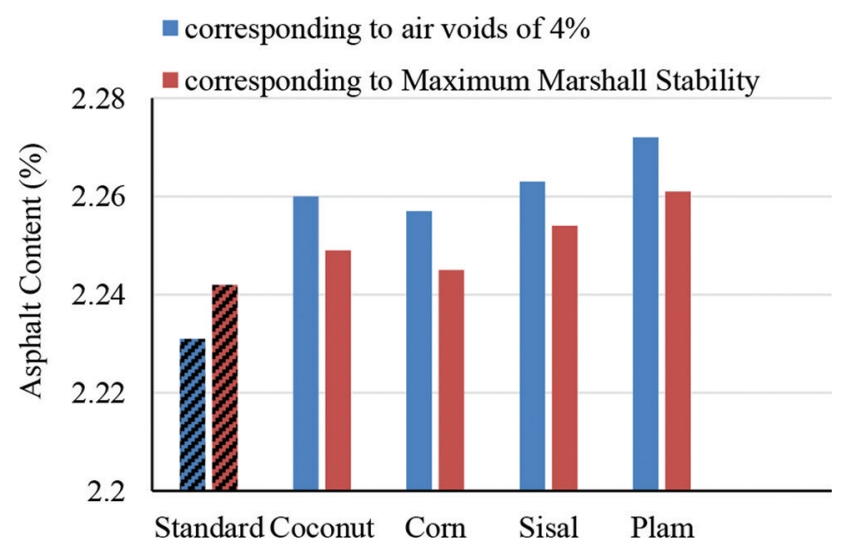

Fig. 9. Effect of fiber type on bulk density.

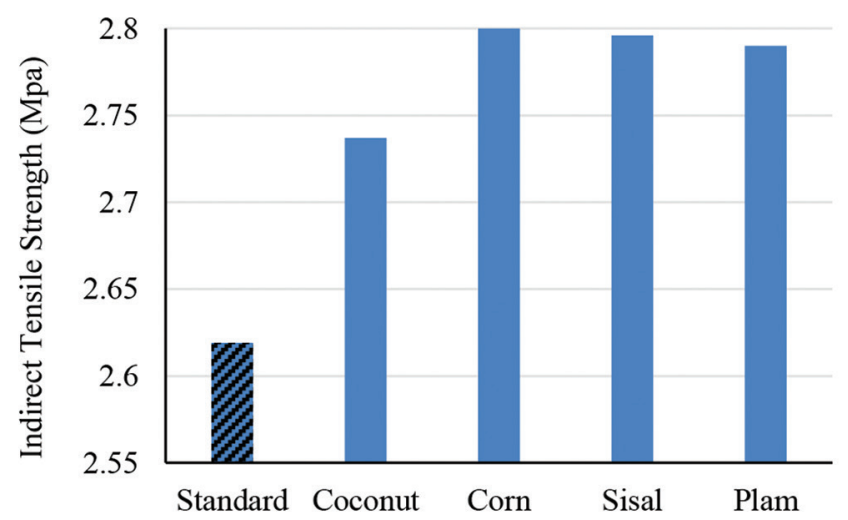

Fig. 10. Effect of natural fiber types on indirect tensile strength (unconditioned).

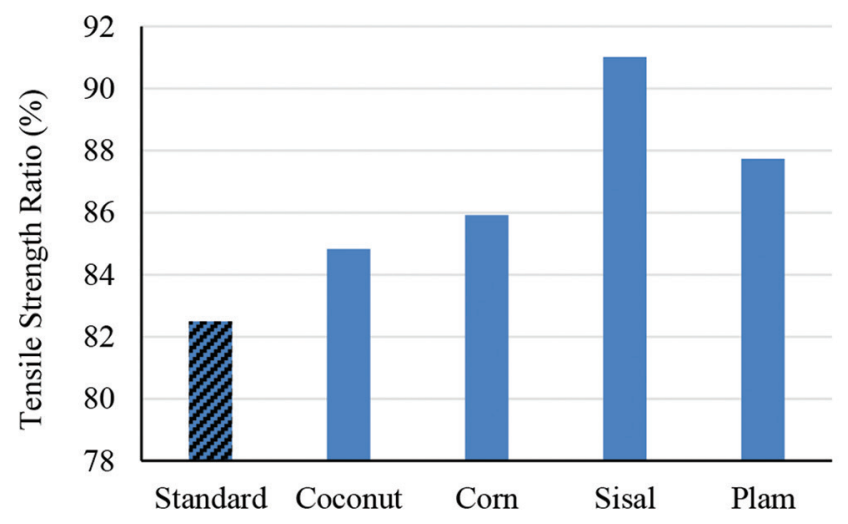

Fig. 11. Effect of natural fiber types on index of retained strength.

natural fiber (sisal fiber) to the aggregate and mixed with the optimum asphalt content. The sisal fiber was cut to four different lengths of $(0.5,1.0,1.5$, and $2.0 \mathrm{~cm})$ and added by $0.2 \%$ of the total weight of the mixture, the results of the Marshall test are shown in Figs. 18-21. According to the results, using asphalt content corresponding to $4 \%$ air voids provided all the Marshall properties within the limitations. The results indicated that the air voids increased when the

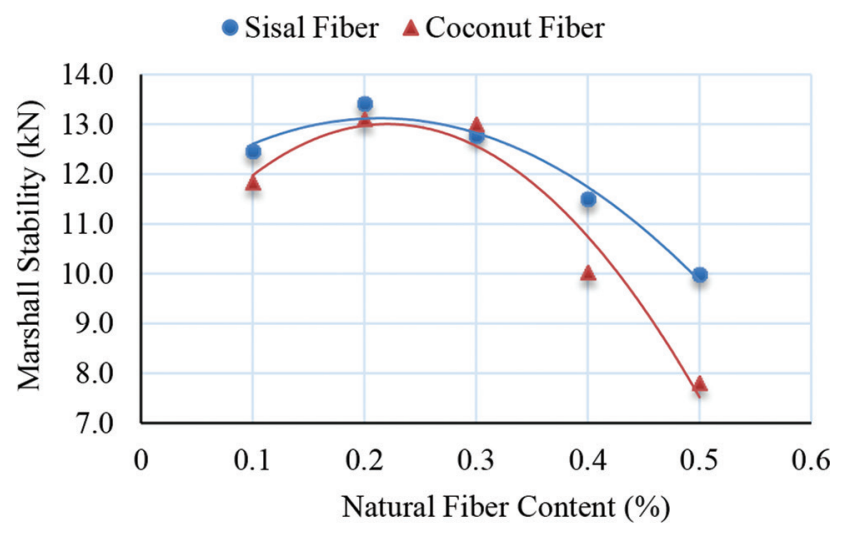

Fig. 12. Effect of fiber content on Marshall stability.

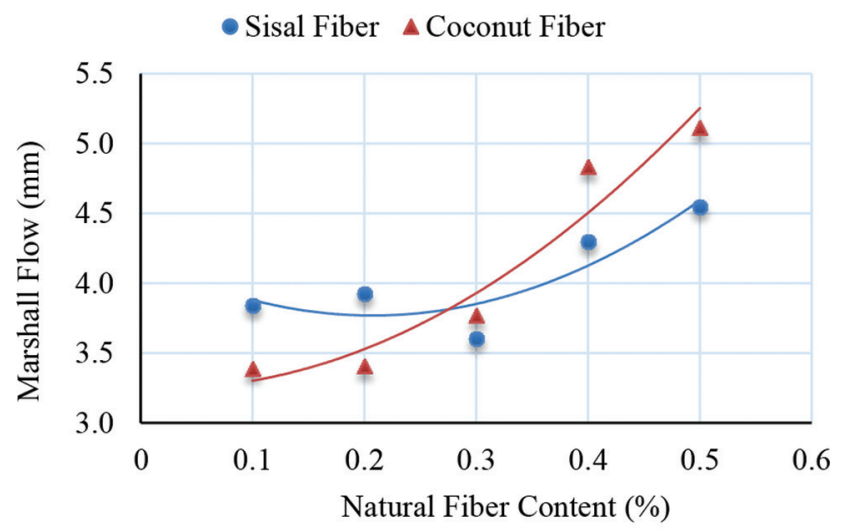

Fig. 13. Effect of fiber content on Marshall flow.

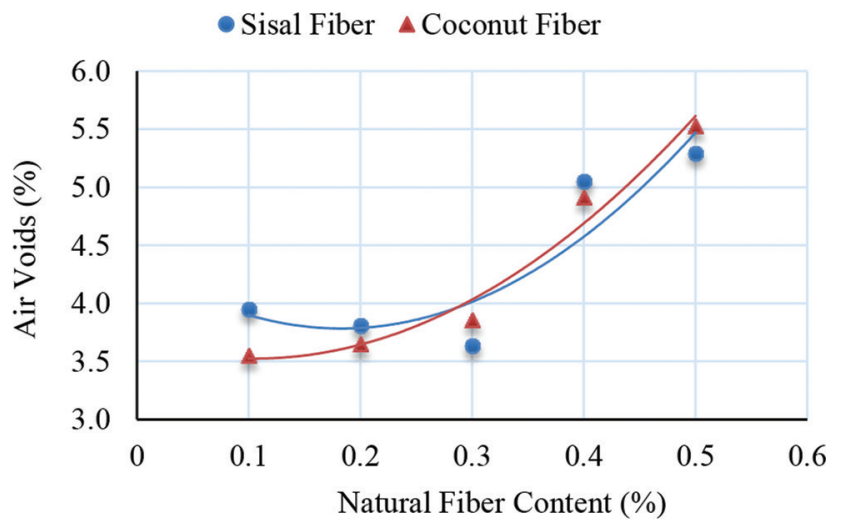

Fig. 14. Effect of fiber content on air voids.

fiber length increase; this can be attributed that the use of too long fibers tends to "ball" in the mix.

The results of indirect tensile strength with respect to different fiber lengths are shown in Fig. 22. It can be observed that when the fiber length increases, the indirect tensile strength increases too up to some extent and starts decreasing. Fig. 23 has a similar behavior of Fig. 22, the tensile strength ratio also increases when the fiber length increases up to a certain limit and starts decreasing. Maybe this is due to the fibers 


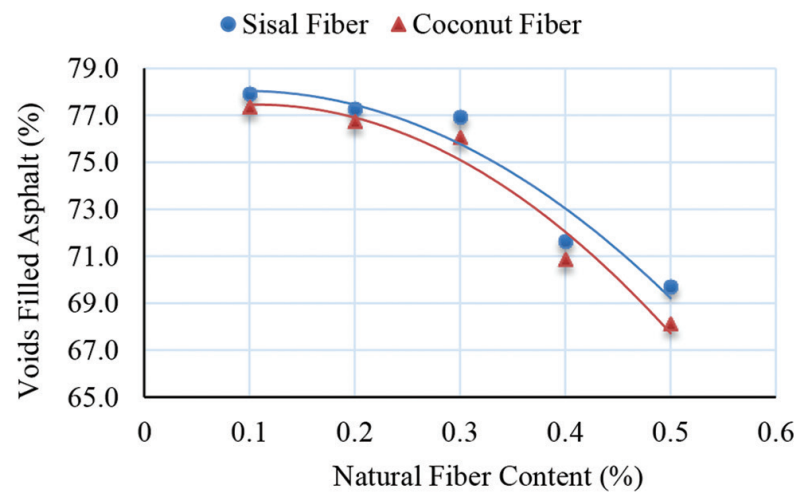

Fig. 15. Effect of fiber content on voids filled asphalt.

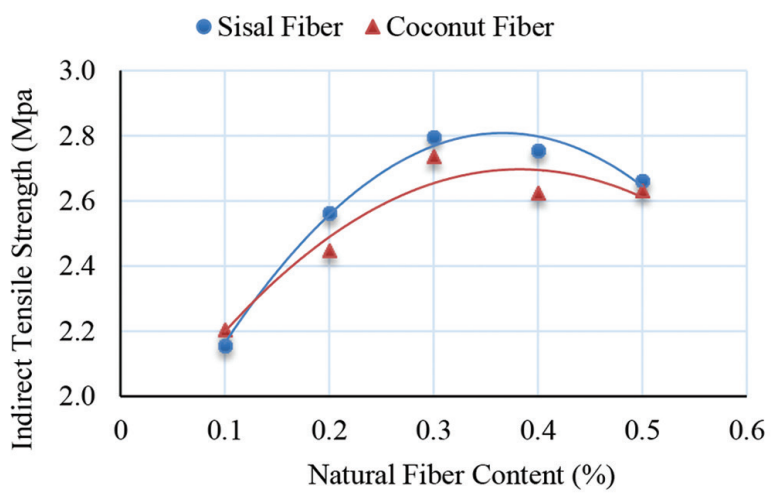

Fig. 16. Effect of natural fiber content on indirect tensile strength (unconditioned).

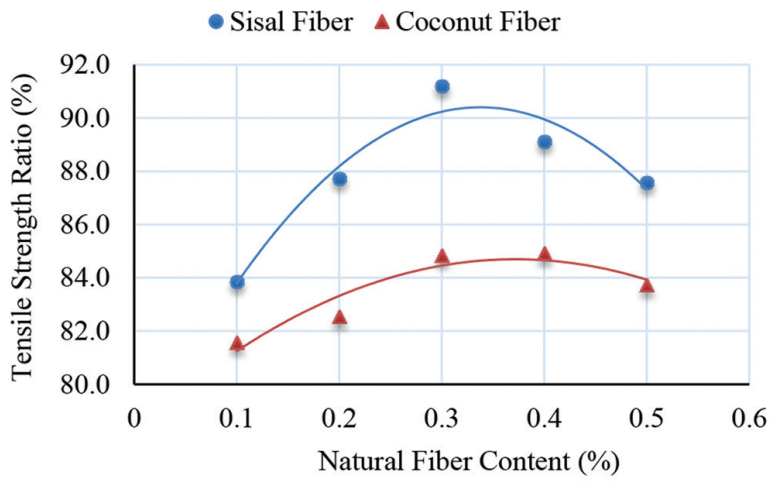

Fig. 17. Effect of natural fiber content on index of retained strength.

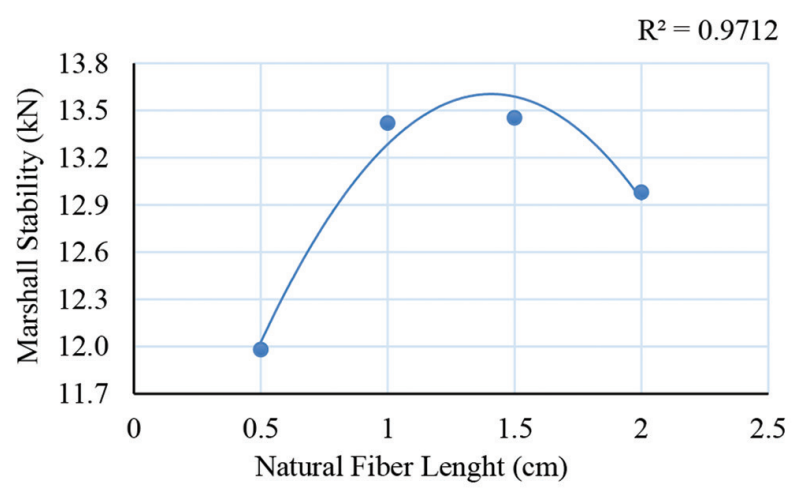

Fig. 18. Effect of natural fiber length on Marshall stability.

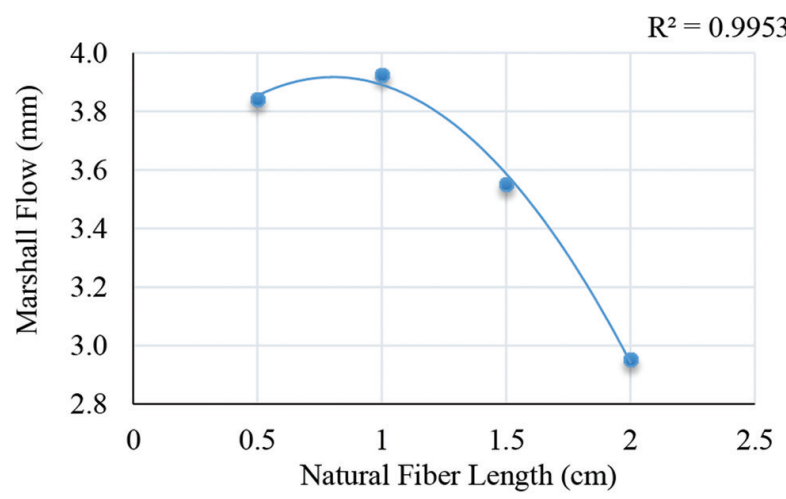

Fig. 19. Effect of natural fiber length on Marshall flow.

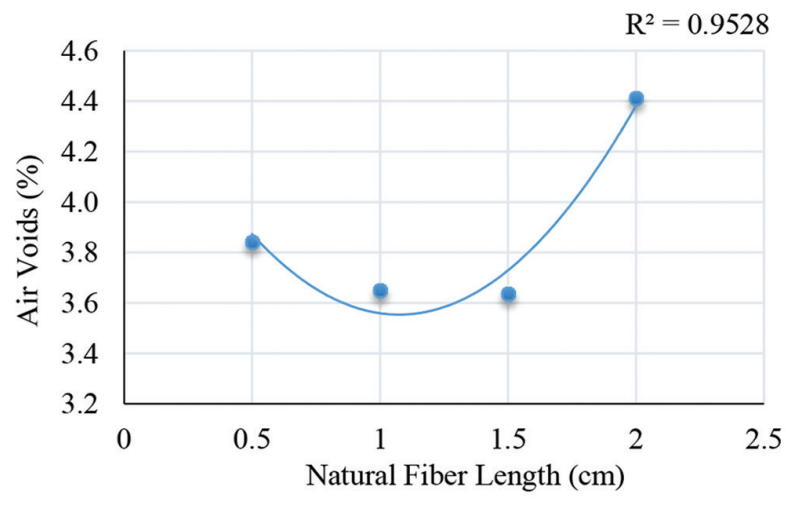

Fig. 20. Effect of natural fiber length on air voids.

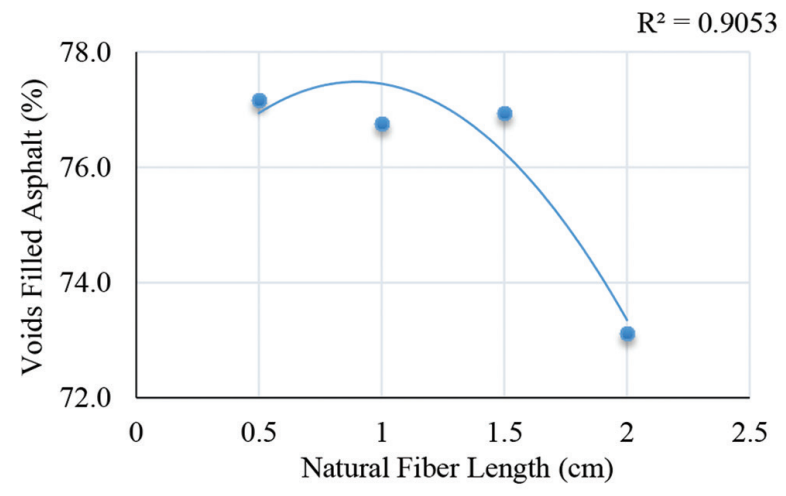

Fig. 21. Effect of natural fiber length on voids filled asphalt.

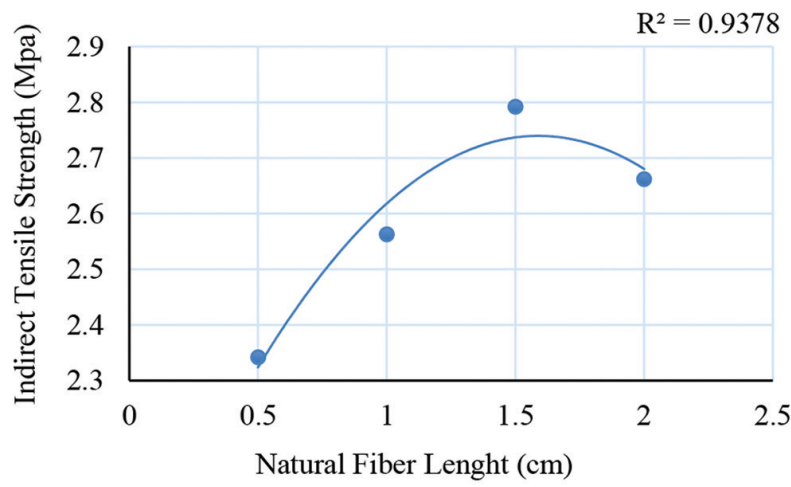

Fig. 22. Effect of natural fiber length on indirect tensile strength (unconditioned) 


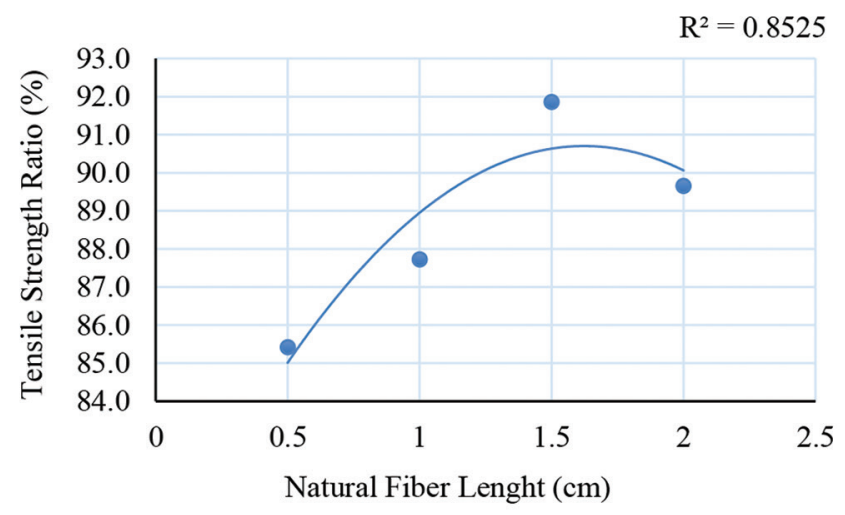

Fig. 23. Effect of natural fiber length on index of retained strength.

reinforcement, which improves the moisture sustainability by increasing the mixture resistance to cracking.

\section{CONCLUSIONS}

From this research, the following conclusions can be drawn based on Marshall test properties and indirect tensile strength test, and clarify the differences between conventional mixture before and after adding the natural fibers.

1. The Marshall test results show that the sisal and palm fibers resulted best mixes considering Marshall criteria according to SORB specifications, where Marshall stability increased by $17 \%$ and $20 \%$ respectively

2. It is also observed that with an increase in fiber content up to $0.2 \%$, air void and flow value decreases, whereas Marshall stability increased by $24 \%$ compared with the conventional mixture

3. It is further observed the use of fiber content $0.3 \%$ increases the resistance to moisture-induced damages as determined in terms of the indirect tensile strength and retained tensile strength ratio

4. The increase in fiber length up to $1.5 \mathrm{~cm}$ caused the Marshall stability increased by $24 \%$ and its retained tensile strength ratio increased to $92 \%$, whereas the increase in fiber length more than $1.5 \mathrm{~cm}$ led to difficulties in the process of mixing the fibers with the mixture.

\section{REFERENCES}

Abdelaziz, M. and Mohamed, R.K., 2010. Fatigue characteristics of stone mastic asphalt mix reinforced with fiber glass, International Journal of the Physical Sciences, 5(12), pp.1840-47.

Ashraf, A., 2012. Fiber Dosage Effects in Asphalt Binders and Hot Mix Asphalt Mixtures. In: A Thesis Presented in Partial Fulfillment of the Requirements for the Degree Master of Science. Arizona State University, Tempe, Arizona.

Bindu, C.S. and Beena, K.S., 2015. Influence of natural fibres on the compressive strength of stone matrix asphalt mixtures. International Journal of Scientific Engineering and Applied Science, 1(6), 445-449.

Brown, S.F., Rowlett, R.D. and Boucher, J.L., 1990. Asphalt modification. In: Proceedings of the Conference on the United States Strategic Highway Research Program: Sharing the Benefits, ICE, Atlanta, Georgia, United States, pp.181-203.

Reena, A., Singh, R. and Shakiya, P., 2009. Corn Fiber: A New Fiber on Horizon, Textile Review, 2009. Available from: https://www.fibre2fashion.com/industryarticle/4455/corn-fiber-a-new-fiber-on-horizon. [Last accessed on $2020 \mathrm{Jul} 01$ ].

Gazia, K.K. and Sukhmanjit, A., 2017. Use of natural fibre and binder quality in stone matrix asphalt mixture. International Journal of Latest Research in Engineering and Computing, 5(3), 73-78.

Hossam, F.H. and Khalifa, A.J., 2005. Effect of organic fibers on opengraded friction course mixture properties. International Journal of Pavement Engineering, 6(1), pp.67-75.

Kavalakuntla, K.K. and Praveen, B.C., 2016. An experimental study of bituminous mixes using a natural fibre. International Journal and Magazine of Engineering Technology, Management and Research, 3(11), pp.906-912.

Saswat, B.D. and Mahabir, P., 2016. A study on use of natural fiber for improvement in engineering properties of dense graded bituminous mixes with coal ash, Transportation in Developing Economies, 2, p.4.

Sigit, P.H., 2013. Evaluation of the addition of short coconut fibers on the characteristics of asphalt mixtures. Civil and Environmental Research, 3(4), pp.63-73.

Standard Practice for Preparation of Bituminous Specimens Using Marshall Apparatus, ASTM D6926-10.

Standard test method for Marshall Stability and Flow of Asphalt Mixtures, ASTM D6927-15.

Standard Test Method for Indirect Tensile (IDT) Strength of Bituminous Mixtures, ASTM D6931-12.

State Organization of Road and Bridges., 2007. Section R9, Hot-Mix Asphalt Concrete Pavement, Revised Edition by Consultant Civil Engineer Nuraddin Saeed Hussain (Issued in Iraq 1986). 